\title{
Congenital muscular dystrophy due to LMNA mutation
}

INSERM

\section{Source}

INSERM. (1999). Orphanet: an online rare disease and orphan drug data base. Congenital muscular dystrophy due to LMNA mutation. ORPHA:157973

Congenital muscular dystrophy due to LMNA mutation is a rare congenital muscular dystrophy characterized by prominent axial hypotonia, dropped head syndrome, predominantly proximal muscle weakness in upper limbs/distal in lower limbs (with absent, poor or lost motor development), joint contractures (initially distal, later proximal), spine rigidity, and early respiratory insufficiency, in the presence of moderately elevated serum creatine kinase. Cardiac arrhythmias and sudden death have been also reported. 